\title{
Netzsch stattet das Thermoanalyse-Labor von SpaceX aus
}

Ds as Hochtemperatur-Labor für Thermische Analyse der Space Exploration Technologies Corp. (SpaceX) wird mit Geräten der Netzsch-Gerätebau $\mathrm{GmbH}$ ausgestattet. Das Labor dient zur Charakterisierung der Materialeigenschaften für Applikationen in der Raumfahrt; die Apparaturen werden für die Feinabstimmung der Eigenschaften bestehender Materialien, aber auch zur Entwicklung neuer Materialien für den Einsatz unter den extremen Bedingungen im Weltall eingesetzt. Ausschlaggebend für die Entscheidung von SpaceX war, dass Netzsch maßgeschneiderte Lösungen anbietet und in der Lage ist, Anpassungen der Geräte an die jeweiligen Anforderungen vorzunehmen.

SpaceX beschreitet einen neuen Weg bei der Herstellung von Raketen und Raum- fahrzeugen. Es ist das erste Privatunternehmen, dem es jemals gelang, ein Raumfahrzeug aus der erdnahen Umlaufbahn auf die Erde zurückzubringen und ein Raumschiff zur Internationalen Raumstation ISS zu entsenden. Im Oktober 2012 konnte die Dragon-Kapsel von SpaceX erneut erfolgreich Nutzlasten zu der ISS und von der ISS zurück zur Erde bringen - der erste offizielle Versorgungstransport für die NASA.

Die Materialien, die bei solchen Einsätzen kritischen Bedingungen standhalten müssen, werden mit den Daten aus der Netzsch-Thermokinetik-Software entwickelt, getestet und optimiert. Dafür ist die Genauigkeit dieser physikalischen Daten ausschlaggebend.

Die Apparaturen werden sowohl zur Messung grundlegender Materialeigenschaf- ten als auch zur Bestimmung anderer thermophysikalischer Eigenschaften eingesetzt. Dazu zählen Phasenumwandlungstemperaturen und -enthalpien, thermischer Längenausdehnungskoeffizient und Kontraktion, Wärmekapazität, Temperatur- und Wärmeleitfähigkeit, aber auch Wärmeübertragungsdaten zur Modellierung und Generierung von Wärmemanagementsystemen.

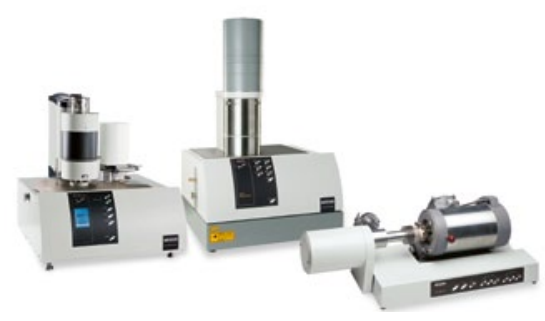

\section{Neuer \\ Entwicklungsleiter bei Vito Irmen}

Mario Kleefisch hat zu Beginn des Jahres 2013 die Leitung der Abteilung Entwicklung \& Labor bei der Vito Irmen $\mathrm{GmbH}$ \& Co. KG in Remagen übernommen. Kleefisch startete seine Karriere nach dem Studium des Chemieingenieurwesens an der Fachhochschule Aachen bei 3M und leitete die letzten 10 Jahre die Entwicklung bei Avery Dennison in Schwelm.

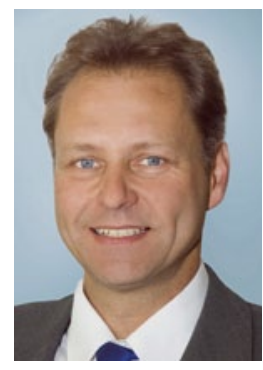

Mario Kleefisch trägt seit Jahresanfang bei Vito Irmen die Verantwortung für die Entwicklung selbstklebender Produkte.

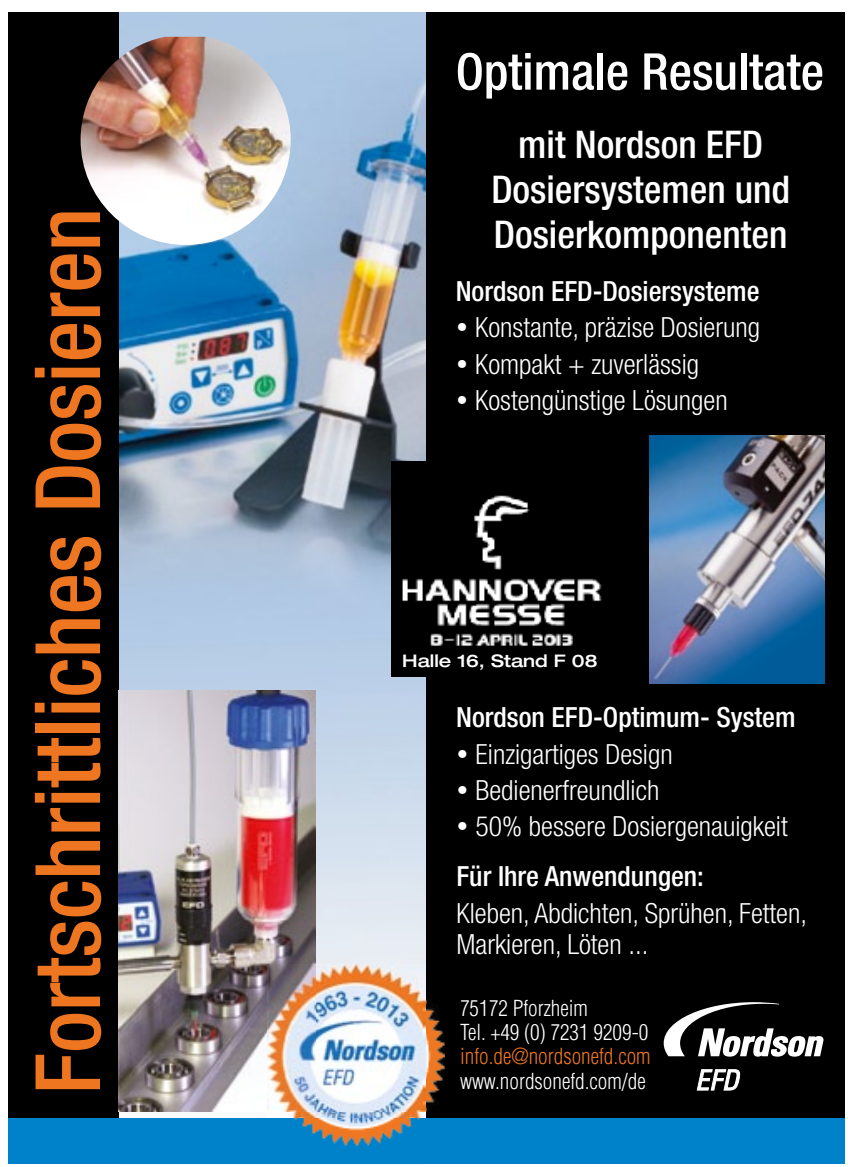

